\title{
Optimización y modificación del método para la detección de ramnolípidos
}

\author{
Optimization and modification of the method for detection of rhamnolipids
}

\section{Takeshi Tabuchi, Diandra Martínez, Manuel Hospinal, Fernando Merino y Susana Gutiérrez*}

Laboratorio de Microbiología y Biotecnología Microbiana, Facultad de Ciencias Biológicas, Universidad Nacional Mayor de San Marcos.

Email Takeshi Tabuchi: takeshitabuchi@hotmail.com

Email Diandra Martínez: diandramartinez1@gmail.com

Email Manuel Hospinal: m.hospinal@hotmail.com

Email Fernando Merino: abilio1007@hotmail.com

*Autor para correspondencia

Email Susana Gutiérrez: sugutimer@gmail.com

\begin{abstract}
Resumen
El uso de biosurfactantes en biorremediación facilita y acelera la degradación microbiana de hidrocarburos. El método del agar CTAB/MB creado por Siegmund y Wagner para el screening de cepas productoras de ramnolípidos (RL), ha sido ampliamente utilizado sin sufrir mejoras significativas en más de 20 años. Con el fin de optimizar la técnica como método cuantitativo, se hicieron placas con agar CTAB/MB y se probaron diferentes variables, tales como tiempo de incubación, refrigeración, concentración de CTAB, presencia de azul de metileno, diámetro de los pozos y volumen del inóculo. Adicionalmente, se desarrolló un nuevo método para detectar el $\mathrm{RL}$ de los halos mediante precipitación con $\mathrm{HCl}$, lo cual permite la observación de un nuevo patrón de halos más fáciles de observar y medir. Esta investigación reafirma que este método no es del todo apropiado para un análisis cuantitativo fino, debido a la dificultad de correlacionar de forma precisa la concentración de RL y el área de los halos formados. La difusión del RL no parece tener un comportamiento simple y existen numerosos factores que afectan la velocidad de migración del RL.
\end{abstract}

Palabras clave: Bromuro de Cetiltrimetilamonio (CTAB); azul de metileno; ramnolípidos, biosurfactantes; Pseudomonas.

\section{Abstract}

Use of biosurfactants in bioremediation, facilitates and accelerates microbial degradation of hydrocarbons. CTAB/MB agar method created by Siegmund \& Wagner for screening of rhamnolipids (RL) producing strains, has been widely used but has not improved significantly for more than 20 years. To optimize the technique as a quantitative method, CTAB/MB agar plates were made and different variables were tested, like incubation time, cooling, CTAB concentration, methylene blue presence, wells diameter and inocula volume. Furthermore, a new method for RL detection within halos was developed: precipitation of RL with $\mathrm{HCl}$, allows the formation a new halos pattern, easier to observe and to measure. This research reaffirm that this method is not totally suitable for a fine quantitative analysis, because of the difficulty to accurately correlate RL concentration and the area of the halos. RL diffusion does not seem to have a simple behavior and there are a lot of factors that affect RL migration rate.

Keyword: Cetyltrimethylammonium Bromide (CTAB); methylene blue; Pseudomonas; rhamnolipids; biosurfactants.

Citación:

Tabuchi T, D. Martínez, M. Hospinal, F. Merino \& S.Gutiérrez. 2015. Optimización y modificación del método para la detección de ramnolípidos. Revista peruana de biología 22(2): 247 - 258 (Octubre 2015). doi: http:// dx.doi.org/10.15381/rpb.v22i2.11359

$\begin{array}{ll}\text { Presentado: } & 11 / 02 / 2015 \\ \text { Aceptado: } & 17 / 07 / 2015\end{array}$

Aceptado: $\quad 17 / 07 / 2015$
Información sobre los autores:

TT y SG Diseñaron la parte experimental y redactaron el manuscrito. TT, DM y MH desarrollaron los experimentos. TT analizó los datos. FM, SG, TT, DM y MH revisaron y aprobaron el manuscrito.

Los autores no incurren en conflictos de intereses.

Fuentes de financiamiento: Los autores agradecen el financiamiento otorgado por el FINCyT mediante el Contrato N²38- FINCyT-IA-2013 para el desarrollo de la presente investigación.

Journal home page: http://revistasinvestigacion.unmsm.edu.pe/index.php/rpb/index

(c) Los autores. Este artículo es publicado por la Revista Peruana de Biología de la Facultad de Ciencias Biológicas, Universidad Nacional Mayor de San Marcos. Este es un artículo de acceso abierto, distribuido bajo los términos de la Licencia Creative Commons Atribución-NoComercial-Compartirlgual 4.0 Internacional.(http://creativecommons.org/licenses/by-nc-sa/4.0/), que permite el uso no comercial, distribución y reproducción en cualquier medio, siempre que la obra original sea debidamente citadas. Para uso comercial, por favor póngase en contacto con editor.revperubiol@gmail.com. 


\section{Introducción}

La contaminación con hidrocarburos representa un serio riesgo para el medioambiente y una amenaza a la salud pública. Ante este problema la biorremediación surge como alternativa de solución. La degradación biológica es usualmente más lenta que el tratamiento químico y físico, y una forma de acelerar este proceso es el uso de biosurfactantes biodegradables, los cuales intensifican la emulsificación de hidrocarburos e incrementan su biodisponibilidad para la degradación microbiana.

Siegmund y Wagner (1991) desarrollaron una técnica de screening para cepas productoras de ramnolípidos (RL). Ellos utilizaron agar mineral con cetiltrimetilamonio bromuro (CTAB) y azul de metileno (MB) para detectar la producción de RL gracias a la formación de unos halos de color azul debido a la interacción entre el ramnolípido, el CTAB y el azul de metileno; aunque el mecanismo exacto por el cual se forman es aún desconocido. La técnica resultó ser bastante eficiente y ventajosa respecto a técnicas anteriores debido a su bajo costo, simplicidad, versatilidad y específicidad. Desde entonces la técnica ha sido ampliamente utilizada por diversos autores para seleccionar cepas productoras de ramnolípidos (Siegmund \& Wagner 1991, Wild, et al. 1997, Yuste, et al. 2000, Christova et al. 2004, Gunther IV et al. 2005, Perfumo et al. 2006, Zhu et al. 2007, Pinzon 2009, Jadhav et al. 2011, Liu et al. 2011).

La técnica de Siegmund y Wagner surgió como alternativa al uso de agar sangre para la detección de biosurfactantes, pues presenta varias ventajas como por ejemplo la no represión catabólica de la producción de biosurfactantes, la no ocurrencia de falsos positivos debido a presencia de hemolisinas, la mayor estabilidad del agar, etc. Adicionalmente, es posible aplicar diferentes condiciones de cultivo directamente sobre el agar (diferentes sustratos o temperaturas) y es posible evaluar colonias individuales. Sin embargo, aunque Pseudomonas aeruginosa (Schoeter,1872) puede crecer sin dificultad, el CTAB inhibe el crecimiento de numerosas bacterias incluso del mismo género Pseudomonas, lo cual se convierte en una desventaja de la técnica, motivo por lo cual Siegmund y Wagner (1991) sugirieron el remplazo del CTAB por otro surfactante catiónico.

Por otro lado, Pinzon y Ju (2009a) llegaron a sugerir una relación lineal entre la concentración de ramnolípidos y la formación de halos de acomplejamiento (halos formados por el complejo RL-CTAB-MB); no obstante, determinaron que el ratio de acomplejamiento molar entre el ramnolípido y el CTAB no es constante y que podría responder a una interacción de naturaleza compleja. Esto sumado al hecho de que el complejo formado está en un estado transicional dependiente del tiempo, hacen que la técnica no sea apropiada para un análisis cuantitativo preciso, por lo que sólo lo recomiendan para selección de cepas y otros propósitos cualitativos (Pinzon \& Ju, 2009a). A pesar de todos estos inconvenientes, defectos y limitaciones, la técnica de Siegmund y Wagner ha permanecido prácticamente invariable por más de 20 años sin mejoras significativas, con excepción de las breves sugerencias dadas por Gunther IV et al. (2005) y Pinzon y Ju (2009a).

Es por tal motivo que en el presente trabajo se explora la técnica desarrollada por Siegmund y Wagner con la finalidad de mejorar y optimizar algunos aspectos de ella. Asi tambien se investiga las condiciones en las que pueda ser posible correlacionar matemáticamente el área de los halos formados con la concentración de ramnolípidos, y de esta manera ajustar la técnica para ser utilizada efectivamente como un método cuantitativo en la selección de cepas superproductoras de ramnolípidos.

\section{Material y métodos}

Se emplearon las cepas Pseudomonas aeruginosa PB25 y Pseudomonas aeruginosa ATCC 9027.

Extracción y obtención del biosurfactante ramnolipídico patrón.- Debido a la dificultad de obtener en Perú ramnolípido purificado, se procedió a producirlo y purificarlo en el laboratorio a partir de la cepa Pseudomonas aeruginosa PB25. Se empleó un cultivo en lote de 4 días de incubación a $35^{\circ} \mathrm{C}$, agitado a 120 RPM y en el medio mínimo mineral de Zhang et al. (2005) suplementado con glicerol y modificado por Giraldo (2012) y Abalos et al. (2002): $\mathrm{CaCl}_{2} 0.02 \mathrm{~g} / \mathrm{L}, \mathrm{KCl} 1 \mathrm{~g} / \mathrm{L}, \mathrm{NaCl}$ $1 \mathrm{~g} / \mathrm{L}, \mathrm{K}_{2} \mathrm{HPO}_{4} 4 \mathrm{~g} / \mathrm{L}, \mathrm{KH}_{2} \mathrm{PO}_{4} 4 \mathrm{~g} / \mathrm{L}$, Glicerol 3\%v/v, $\mathrm{NaNO}_{3}$ $2.5 \mathrm{~g} / \mathrm{L}, \mathrm{MgSO}_{4} \cdot 7 \mathrm{H}_{2} \mathrm{O} 0.2 \mathrm{~g} / \mathrm{L}$, solución de elementos traza $2 \mathrm{ml} / \mathrm{L}\left(\mathrm{H}_{3} \mathrm{BO}_{3} 0.26 \mathrm{~g} / \mathrm{L}, \mathrm{Na}_{2} \mathrm{MoO}_{4} 0.6 \mathrm{~g} / \mathrm{L}, \mathrm{CuSO}_{4} \cdot 5 \mathrm{H}_{2} \mathrm{O}\right.$ $\left.0.5 \mathrm{~g} / \mathrm{L}, \mathrm{MnSO}_{4} 0.5 \mathrm{~g} / \mathrm{L}, \mathrm{ZnSO}_{4} \cdot 7 \mathrm{H}_{2} \mathrm{O} 0.7 \mathrm{~g} / \mathrm{L}\right)$.

Se procedió a una purificación mediante precipitación ácida y extracción por solventes apolares (cloroformo y éter etílico), adaptado de Giraldo (2012).

Evaluación sobre placas de agar CTAB/MB.- Para evaluar las diferentes variables se hicieron placas con agar CTAB/MB según Siegmund \& Wagner (1991), siguiendo las recomendaciones de Gunther IV et al. (2005) y de Pinzon y Ju (2009a). Para todas las pruebas, los parámetros utilizados fueron los que figuran en esta sección salvo que se indique lo contrario en la prueba correspondiente.

Se preparó agar mineral Siegmund y Wagner (Agar SW: Glicerol $20 \mathrm{~g} / \mathrm{L}, \mathrm{KH}_{2} \mathrm{PO}_{4} 0.7 \mathrm{~g} / \mathrm{L}, \mathrm{Na}_{2} \mathrm{HPO}_{4} \cdot 2 \mathrm{H}_{2} \mathrm{O} 0.9 \mathrm{~g} / \mathrm{L}$, $\mathrm{NaNO}_{3} 2 \mathrm{~g} / \mathrm{L}, \mathrm{mgSO}_{4} \cdot \mathrm{H}_{2} \mathrm{O} 0.4 \mathrm{~g} / \mathrm{L}, \mathrm{CaCl}_{2} \cdot 2 \mathrm{H}_{2} \mathrm{O} 0.1 \mathrm{~g} / \mathrm{L}$, solución de elementos traza $2 \mathrm{~mL} / \mathrm{L}$ y agar-agar $17 \mathrm{~g} / \mathrm{L}$ ) suplementado con $0.005 \mathrm{~g} / \mathrm{L}$ de azul de metileno (MB) y $0.2 \mathrm{~g} / \mathrm{L}$ de cetiltrimetilamonio bromuro (CTAB). El agar CTAB/MB fue esterilizado en autoclave por 15 minutos a $121^{\circ} \mathrm{C}$.

Para asegurar la uniformidad de las placas, se seleccionaron placas Petri con las mismas medidas (diámetro interno: $\sim 90 \mathrm{~mm}$ ) y se dispensaron $15 \mathrm{ml}$ de agar CTAB/MB en cada una, para lograr un espesor del agar de $2 \mathrm{~mm}$.

En el agar se hicieron perforaciones con un sacabocados estéril de $5.5 \mathrm{~mm}$ de diámetro y se adicionaron $20 \mu \mathrm{L}$ de una solución de ramnolípidos (RL) en las siguientes concentraciones: 3.125; $6.25 ; 12.5 ; 25 ; 50 ; 75 ; 100 ; 150 ; 200$ y $400 \mathrm{~g} / \mathrm{L}$. Las placas fueron incubadas a $35^{\circ} \mathrm{C}$ por 24 horas y luego refrigeradas a 4 ${ }^{\circ} \mathrm{C}$ por 24 horas adicionales (Gunther IV, et al., 2005).

Posteriormente, los halos de las placas fueron revelados mediante una nueva técnica y el área de los halos formados fue medido mediante el software de procesamiento de imágenes ImageJ $1.49 \mathrm{e}$ (Rasband, 2013). Cada experimento se realizó por triplicado y se obtuvo la media del área de los halos de cada concentración de RL.

Nuevo método de revelado de las placas.- Se desarrolló un nuevo método para detectar el RL de los halos disminuyendo el $\mathrm{pH}$ del agar mediante la adición de $\mathrm{HCl} 1 \mathrm{~N}$ lo que precipita los ramnolípidos $(\mathrm{RL})$ previamente acomplejados. 

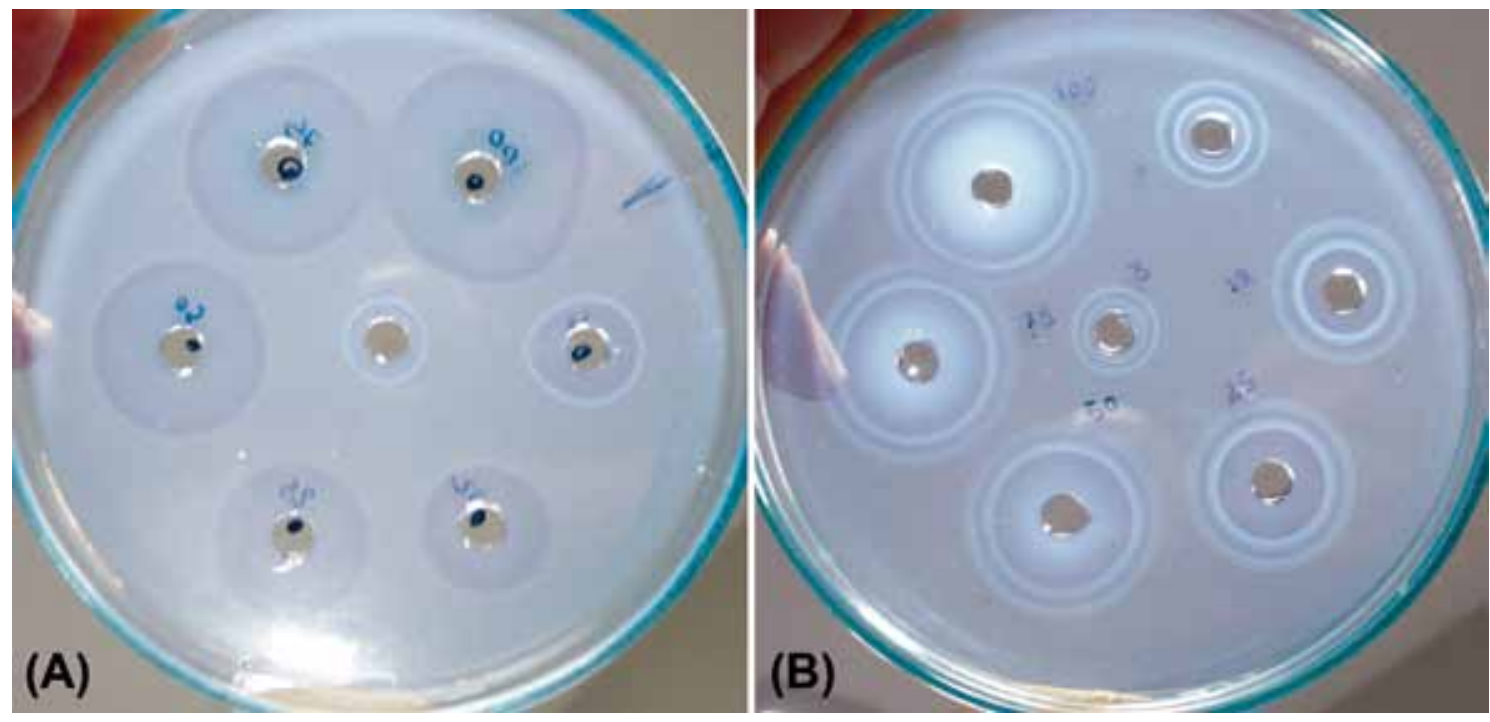

Figura 1. Halos de acomplejamiento $(\mathrm{A})$ halos de precipitación sin $\mathrm{HCl}$ y $(\mathrm{B})$ halos de precipitación con $\mathrm{HCl}$. Los ramnolípidos precipitados por el $\mathrm{HCl}$, forman halos concéntricos blancos alrededor de los pocillos y también en el lugar donde previamente se habían formado los halos de acomplejamiento

Evaluación del efecto del azul de metileno en el agar.- Para evaluar si el azul de metileno es indispensable en la técnica se prepararon placas con agar SW suplementado con CTAB; con o sin azul de metileno; y se probaron diferentes concentraciones de RL.

Influencia del diámetro de los pocillos, volumen de inóculo y concentración de RL.- Para evaluar si el área de los pocillos, el volumen de inóculo y la concentración de RL tienen influencia en la difusión del ramnolípido y la formación de los halos, se perforaron pocillos de $-3.5 \mathrm{~mm}$ y $-5.5 \mathrm{~mm}$ de diámetro y se adicionó dentro de los pocillos volúmenes de $10 \mu \mathrm{L}, 20 \mu \mathrm{L}$, $30 \mu \mathrm{L}, 40 \mu \mathrm{L}$ y $50 \mu \mathrm{L}$ de soluciones de $\mathrm{RL}$ en concentraciones de 50 y $100 \mathrm{~g} / \mathrm{L}$.

Evaluación del tiempo de incubación y del efecto del frío.- Para establecer si existe una dependencia del tiempo de incubación en la difusión del ramnolípido y la formación de los halos, y si existe algún límite para dicha difusión, se incubaron diferentes concentraciones de RL $(3.125,6.25,12.5,25,50$, 100 y $200 \mathrm{~g} / \mathrm{L}$ ) por $12,24,48,72$ y 96 horas a $35^{\circ} \mathrm{C}$ seguido de 24 horas en refrigeración. Así mismo para verificar el efecto de la temperatura se probaron placas a 24 horas de incubación pero sin refrigeración.

Evaluación del efecto de la concentración de CTAB en el agar.- Para evaluar el efecto del CTAB en la formación de los halos, se prepararon placas con las siguientes concentraciones de CTAB: 0.05, 0.1, 0.2, 0.3 y 0.4 g/L. En cada concentración de CTAB se probó diferentes concentraciones de RL (3.125, 6.25, 12.5, 25, 50, 75, 100, 150, 200, $400 \mathrm{~g} / \mathrm{L})$.

Análisis estadístico de los datos.- Con los datos se hicieron las gráficas respectivas y las correlaciones estadísticas necesarias utilizando las medias y las desviaciones estándar de las mediciones de las áreas de los halos. Para establecer la homogeneidad de la varianzas se aplicó la prueba de Levene; mientras que para verificar la normalidad de los datos se aplicó el test de ShapiroWilk. Para establecer la correlación lineal entre dos variables se aplicó un análisis de regresión lineal simple. Dependiendo del caso, se aplicó la prueba ANOVA o la prueba t-Student para comparar las medias y encontrar diferencias significativas. Se realizó la prueba post-hoc HSD de Tukey para realizar las comparaciones múltiples tras el análisis ANOVA. Se emplearon los software MS Office Excel 2007, XLSTAT 2009 y SPSS v15.0 para la realización de las pruebas estadísticas y los gráficos.

\section{Resultados}

Nuevo método de revelado de las placas.- El RL precipitado por el $\mathrm{HCl}$, forma halos concéntricos blancos alrededor de los pocillos en el lugar donde previamente se habían formado los halos de acomplejamiento (Fig. 1).

Este método permite la observación de un nuevo patrón descrito (Fig. 2). Con la nueva técnica se ha podido visualizar y

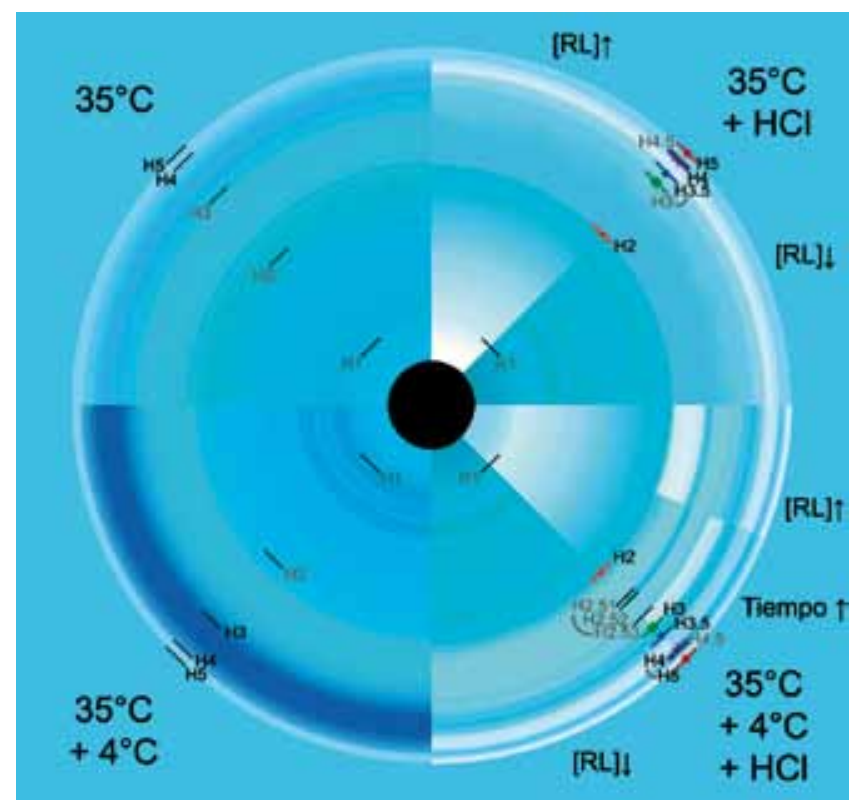

Figura 2. Esquematización de los diversos halos formados bajo diferentes condiciones. Halos de acomplejamiento (izquierda: $35^{\circ} \mathrm{C}$ y $35^{\circ} \mathrm{C}+4^{\circ} \mathrm{C}$ ) y halos de precipitación (derecha: $35^{\circ} \mathrm{C}+\mathrm{HCl}$ y $35^{\circ} \mathrm{C}+4{ }^{\circ} \mathrm{C}+\mathrm{HCl}$ ). En gris aquellos halos que sólo son observables bajo ciertas condiciones. 
Tabla 1. Descripción de los halos formados bajo diferentes condiciones de incubación y revelado.

\begin{tabular}{|c|c|c|c|c|c|}
\hline & $\begin{array}{l}\underset{\mathcal{I}}{\mathbb{I}} \\
\text { Ù } \\
\stackrel{\circ}{\mathrm{n}}\end{array}$ & 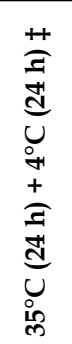 & 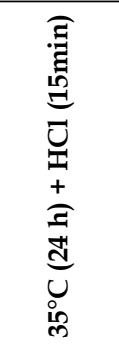 & 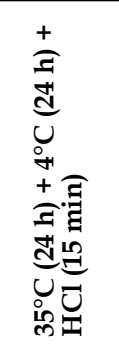 & \\
\hline \multirow[t]{2}{*}{ Halo translúcido interno } & (H1) & (H1) & $((\mathrm{H} 1))$ & $((\mathrm{H} 1))$ & Halo translúcido interno \\
\hline & & & $(\mathrm{H} 1.5)$ & (H1.5) & Halo azul / Halo blanco ([RL]个) \\
\hline \multirow[t]{4}{*}{ Halo azul translúcido } & $((\mathrm{H} 2))$ & $(\mathrm{H} 2)$ & $\mathrm{H} 2$ & $\mathrm{H} 2$ & $1^{\circ}$ Frontera Translúcido-Opaco \\
\hline & & & $\left(\mathrm{H} 2.5_{1}\right)$ & $\left(\mathrm{H} 2.5_{1}\right)$ & Halo opaco blanco ([RL]个) \\
\hline & & & $\left(\left(\mathrm{H} 2.5_{2}\right)\right)$ & $\left(\left(\mathrm{H} 2.5_{2}\right)\right)$ & $1^{\circ}$ Halo intermedio $([R L] \uparrow)$ \\
\hline & & & $\left(\left(\mathrm{H} 2.5_{3}\right)\right)$ & $\left(\left(\mathrm{H} 2.5_{3}\right)\right)$ & $2^{\circ}$ Halo intermedio (tiempo incub. $>48 \mathrm{~h}$ ) \\
\hline \multirow[t]{2}{*}{ Frontera del Halo azul traslúcido } & $((\mathrm{H} 3))$ & $\mathrm{H} 3$ & (H3) & $\mathrm{H} 3$ & Frontera del Halo opaco \\
\hline & & & H3.5 & H3.5 & $2^{\circ}$ Frontera Translúcido-Opaco \\
\hline \multirow[t]{2}{*}{ Halo azul oscuro / marrón } & $\mathrm{H} 4$ & $\mathrm{H} 4$ & $\mathrm{H} 4$ & $\mathrm{H} 4$ & Frontera del Halo opaco \\
\hline & & & $(\mathrm{H} 4.5)$ & (H4.5) & Inicio del anillo exterior \\
\hline Anillo exterior blanco & H5 & $\mathrm{H} 5$ & H5 & H5 & Anillo exterior blanco translúcido \\
\hline
\end{tabular}

‡ Descrito por Pinzon \& Ju (2009a)

(H\#) Difícil de observar o medir, sólo visible bajo condiciones específicas, a veces difuso o no visible.

$((\mathrm{H \# )})$ Extremadamente difícil de observar o medir, sólo visible bajo condiciones específicas, usualmente difuso o no visible.

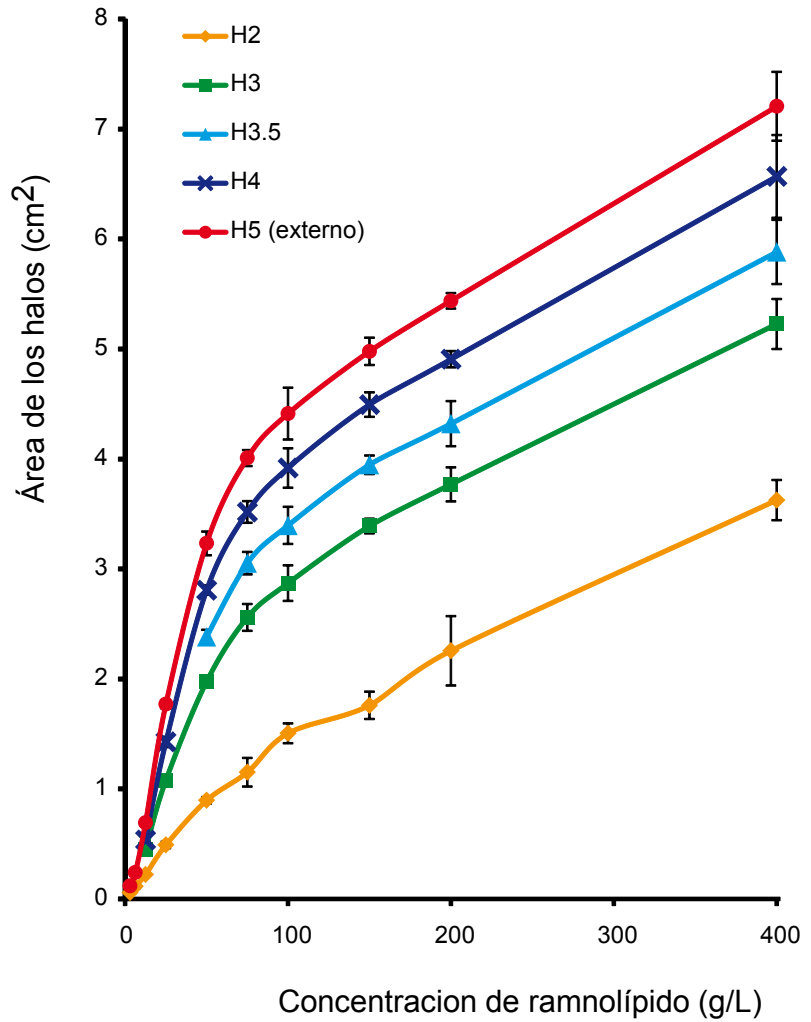

Figura 3. Gráfico del área de los halos de precipitación en placas de agar CTAB/MB. Barras verticales indican la desviación estándar de cada punto.

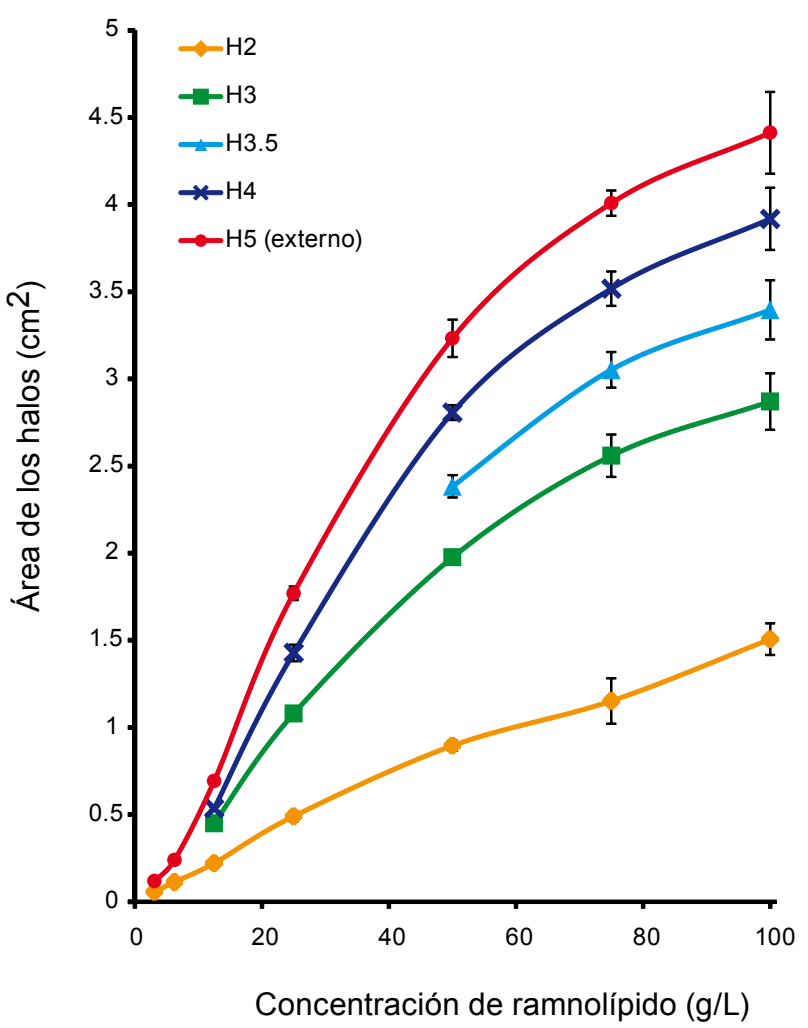

Figura 4. Gráfico del área de los halos de precipitación en placas de agar CTAB/MB. Detalle de las concentraciones de $\mathrm{RL}$ menores a $100 \mathrm{~g} / \mathrm{L}$. Barras verticales indican la desviación estándar de cada punto. 


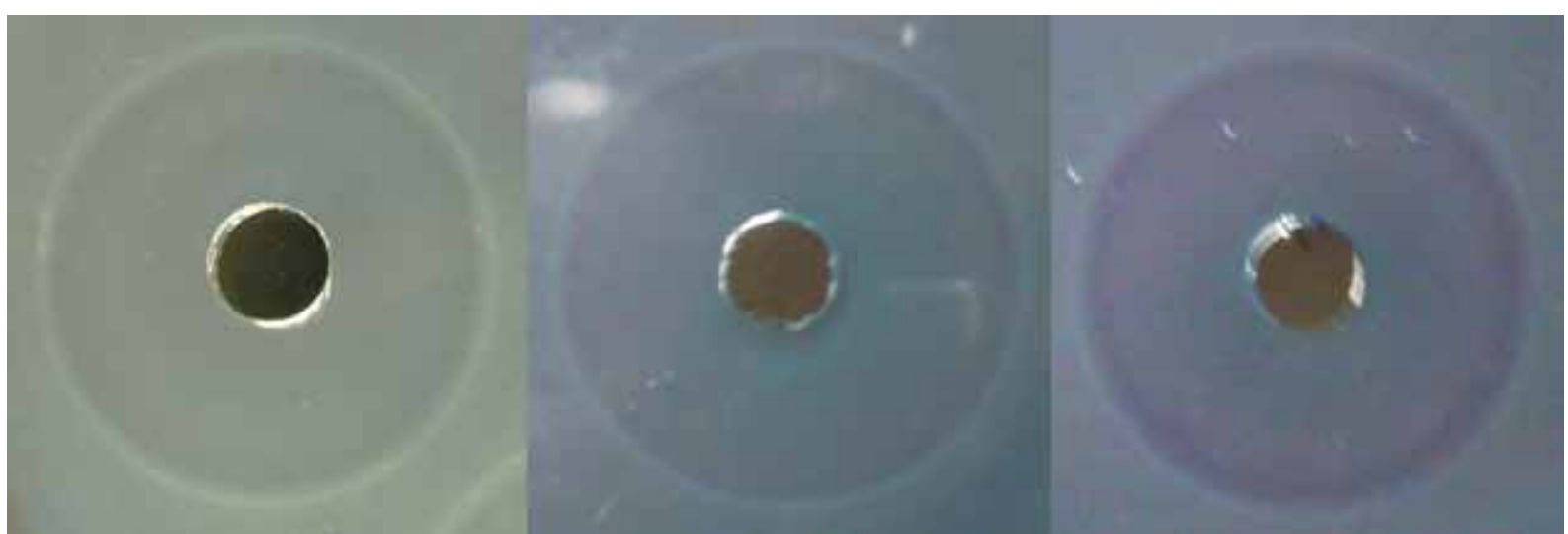

Figura 5. Halos de acomplejamiento. (A) Agar CTAB sin MB, (B) Agar CTAB/MB con 24 horas de incubación a $35^{\circ} \mathrm{C}$. (C) Agar $\mathrm{CTAB} / \mathrm{MB}$ con 24 horas de incubación a $35^{\circ} \mathrm{C}$, seguido por 24 horas de refrigeración (post-incubación a $4^{\circ} \mathrm{C}$ ).

describir hasta 11 zonas de halos no reportados antes del presente trabajo (Tabla 1). Los límites de alguna de las zonas de los halos de precipitación se corresponden con las zonas de los halos de acomplejamiento descritas por Pinzon y Ju (2009a); pero entre ellos se aprecia la aparición de otros halos intermedios que no se visualizan con la técnica convencional. A los límites de cada zona ( $\mathrm{H}$ : halo) principal que se corresponde con un halo descrito por Pinzon y Ju (2009a) se le ha asignado un número entero $(\mathrm{H} \underline{\mathrm{X}})$, dichos halos son en general los más constantes, visibles y distinguibles. Entre ellos pueden aparecer halos opacos (RL precipitado) o zonas translúcidas (separación entre halos); a sus límites se les ha asignado un número racional intermedio a los halos que los flanquean (HX.5). Ocasionalmente, puede aparecer más de un halo o zona translúcida intermedia, por lo que a cada una se le ha asignado un subíndice correlativo (HX.5 . $_{\underline{Y}}$. Dependiendo de ciertas condiciones como concentración o tiempo de incubación, algunas de estas regiones son más o menos visibles, se separan más y se distinguen mejor las unas de las otras; aunque por lo general algunas no son visibles del todo o se ven superpuestas por lo que aparecen como una sola banda gruesa.

Relación entre concentración de RL y área de los halos.La medición inicial de las áreas de los halos y la gráfica de sus promedios mostró una curva claramente no-lineal con un punto de quiebre alrededor de 75 a $100 \mathrm{~g} / \mathrm{L}$ de concentración de RL (Figs. 3 y 4). Debajo de este punto, la curva pareciera ser polinómica o logística; mientras que por encima, la curva pareciera ser lineal sin un punto de saturación aparente.

Evaluación del efecto del azul de metileno en el agar.- En la técnica convencional el azul de metileno (MB) otorga la coloración azul característica de los halos de acomplejamiento, dicho color se intensifica cuando las placas son refrigeradas (Fig. 5).
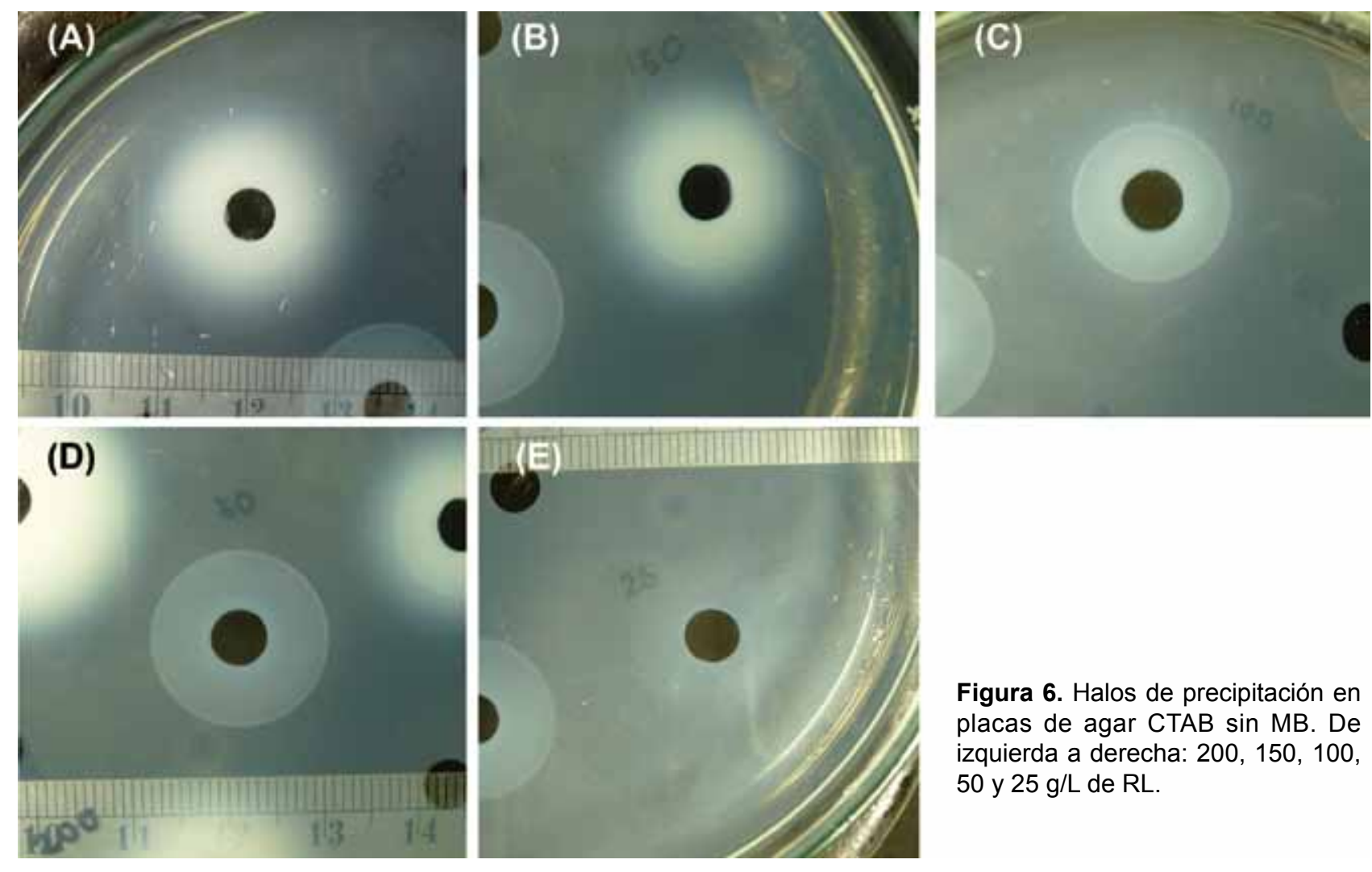

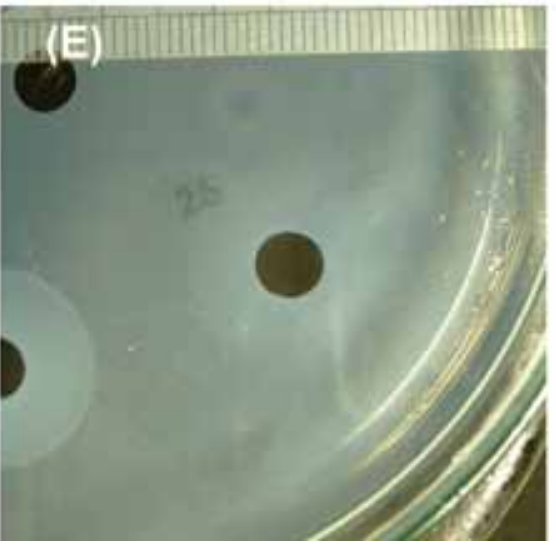

Figura 6. Halos de precipitación en placas de agar CTAB sin MB. De izquierda a derecha: 200, 150, 100, 50 y $25 \mathrm{~g} / \mathrm{L}$ de $\mathrm{RL}$. 


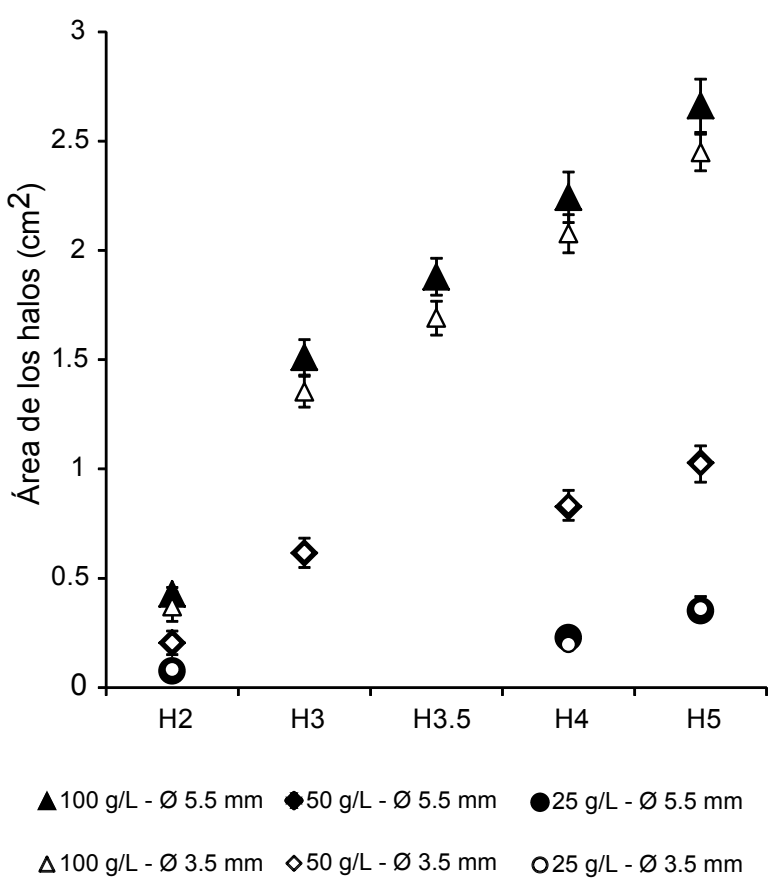

Figura 7. Comparación de las área de los halos formados en los diferentes diámetros de pocillo con diferentes concentraciones de RL. Barras verticales indican la desviación estandar de cada punto.

Con la nueva técnica de revelado, se ha podido observar que dependiendo de la concentración de RL, los halos de precipitación que se forman en las placas sin $\mathrm{MB}$ se muestran difusos y/o poco definidos, llegando al punto que a veces ni siquiera se distinguen ni se diferencian los halos internos (Fig. 6).

Influencia del diámetro de los pocillos y el volumen de inóculo.- Se encontró que el volumen máximo que los pocillos de $5.5 \mathrm{~mm}$ de diámetro podían contener $40 \mu \mathrm{L}$ sin que el riesgo de derrames accidentales, mientras que el volumen máximo de los de $3.5 \mathrm{~mm}$ de diámetro fue de $10 \mu \mathrm{L}$.

Se aplicaron dos pruebas estadísticas: la prueba de Levene para igualdad de varianzas y la prueba T-Student para diferencia de medias. En todos los casos la prueba de Levene mostró que las varianzas eran iguales $\left(\sigma_{1}^{2}=\sigma_{2}^{2}\right)$ ya que el valor de significación de la prueba era mayor que el nivel de significación establecido $\mathrm{a}=0.05$.

Con relación a la media del área, los halos tienden a ser ligeramente mayores cuando el pocillo es de mayor tamańo y las concentraciones son mayores, sobre todo a $100 \mathrm{~g} / \mathrm{L}$ donde la desviación se vuelve evidente; no obstante, la prueba t-Student para igualdad de medias, muestra que no existen diferencias realmente significativas en el área de los halos $\left(\mu_{1}=\mu_{2}\right)$ en relación al tamaño de los pocillos para un mismo volumen de inóculo $(10 \mu \mathrm{L})$. En todos los casos el valor de significación bilateral de la prueba es mayor que el nivel de significación establecido $\mathrm{a} / 2=0.025$. Gráficamente los puntos de ambos casos $(5.5 \mathrm{~mm}$ y $3.5 \mathrm{~mm}$ ) se observan superpuestos sobre todo en las concentraciones menores (Fig. 7).

Por su parte, la prueba de regresión lineal del área de los halos respecto al volumen del inóculo muestra un $\mathrm{R}^{2}$ por encima de 0.96 lo que indica una aparente relación lineal. No obstante, a

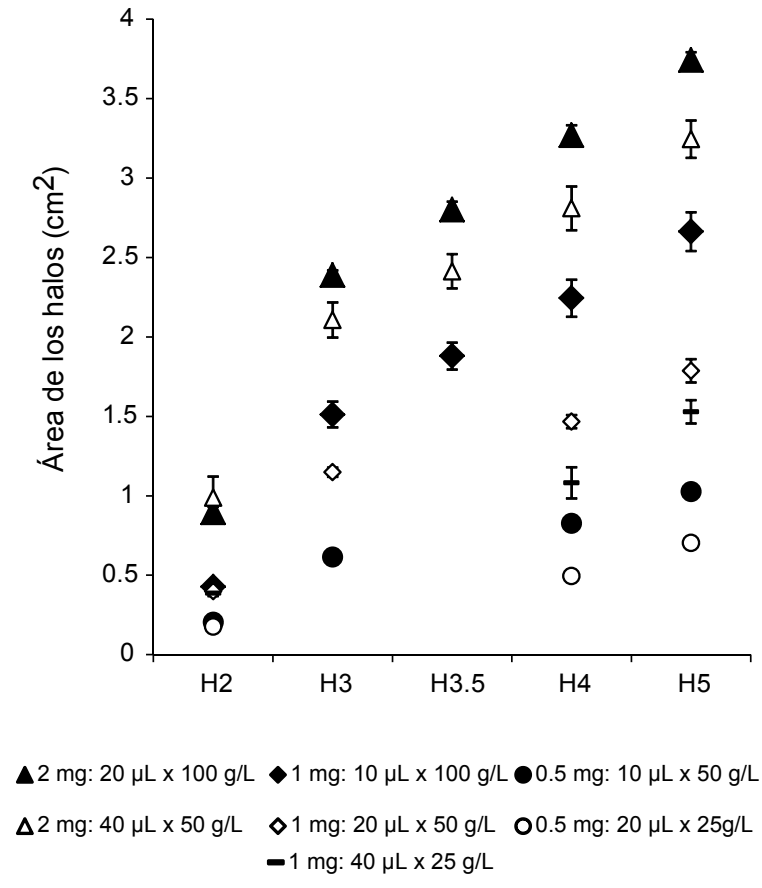

Figura 8. Gráfico de las medias del área de los halos formados por los inóculos con el mismo contenido de RL. Barras verticales indican la desviación estandar de cada punto.

concentraciones mayores y volúmenes mayores, se hace evidente una pequeńa distorsión en las curvas.

En relación a la equivalencia de cantidad de ramnolípido inoculado con respecto al volumen, se encontró diferencias significativas (sig. $<\mathrm{\alpha} / 2=0.025$ ) entre las medias de las áreas de los halos H3, H3.5, H4 y H5 de diferentes inóculos cuyo contenido de ramnolípido (concentración $\times$ volumen) era supuestamente el mismo. En la Figura 8 claramente se puede observar que los puntos no coinciden a pesar de tener contenidos similares de RL.

Evaluación del tiempo de incubación y del efecto del frío.- Las gráficas (Figs. 9 y 10) muestran que el tamaño de los halos es dependiente del tiempo de incubación: a mayor tiempo de incubación mayor tamaño alcanzan los halos. En las gráficas se puede apreciar que el RL de las concentraciones más bajas (3.125, 6.25 y $12.5 \mathrm{~g} / \mathrm{L})$ aparentemente logran quedar inmovilizados dentro de las 12 horas de incubación a $35^{\circ} \mathrm{C}$ y 24 horas a $4{ }^{\circ} \mathrm{C}(12 \mathrm{~h}+\mathrm{R})$, alcanzando una aparente relación lineal entre la concentración del RL y el área de los halos formados no obstante, las concentraciones mayores a $25 \mathrm{~g} / \mathrm{L}$ no logran siquiera acercarse a dicho punto en el tiempo máximo programado en el experimento $\left(96 \mathrm{~h}+\mathrm{R}: 96 \mathrm{~h}\right.$ a $35^{\circ} \mathrm{C}$ y $24 \mathrm{~h}$ a $\left.4{ }^{\circ} \mathrm{C}\right)$.

La prueba ANOVA indica que no existen diferencias significativas $(a=0.05)$ en las áreas de los halos (variable respuesta) de las concentraciones más bajas (3.125, 6.25 y $12.5 \mathrm{~g} / \mathrm{L}$ ) en relación a todos los tiempos de incubación (tratamiento); gráficamente se puede observar que dichas concentraciones forman líneas horizontales (Fig. 11) lo que indica que el área es la misma independientemente del tiempo de incubación.

En las concentraciones más altas, además de encontrar diferencias significativas cuando se comparan pares de tiempos suce- 


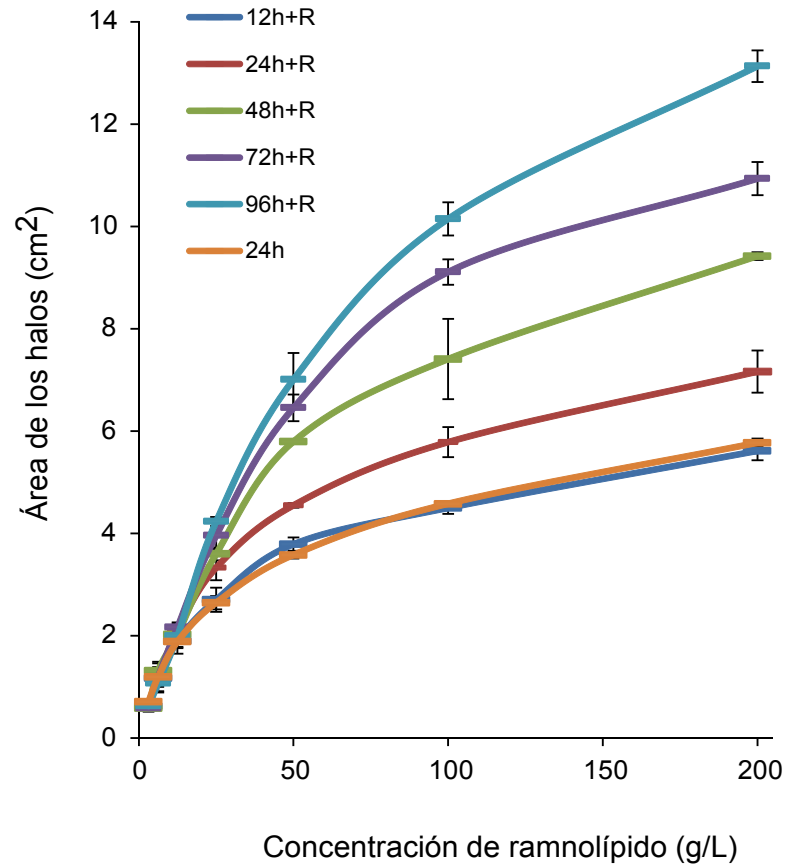

Figura 9. Gráfico del área de los halos $\mathrm{H} 5$ en placas de agar $\mathrm{CTAB} / \mathrm{MB}$ incubadas a diferentes tiempos. Placas con 24 horas de post-incubación a $4{ }^{\circ} \mathrm{C}$ (refrigeración) se indican con "+R". Barras verticales indican la desviación estandar de cada punto.

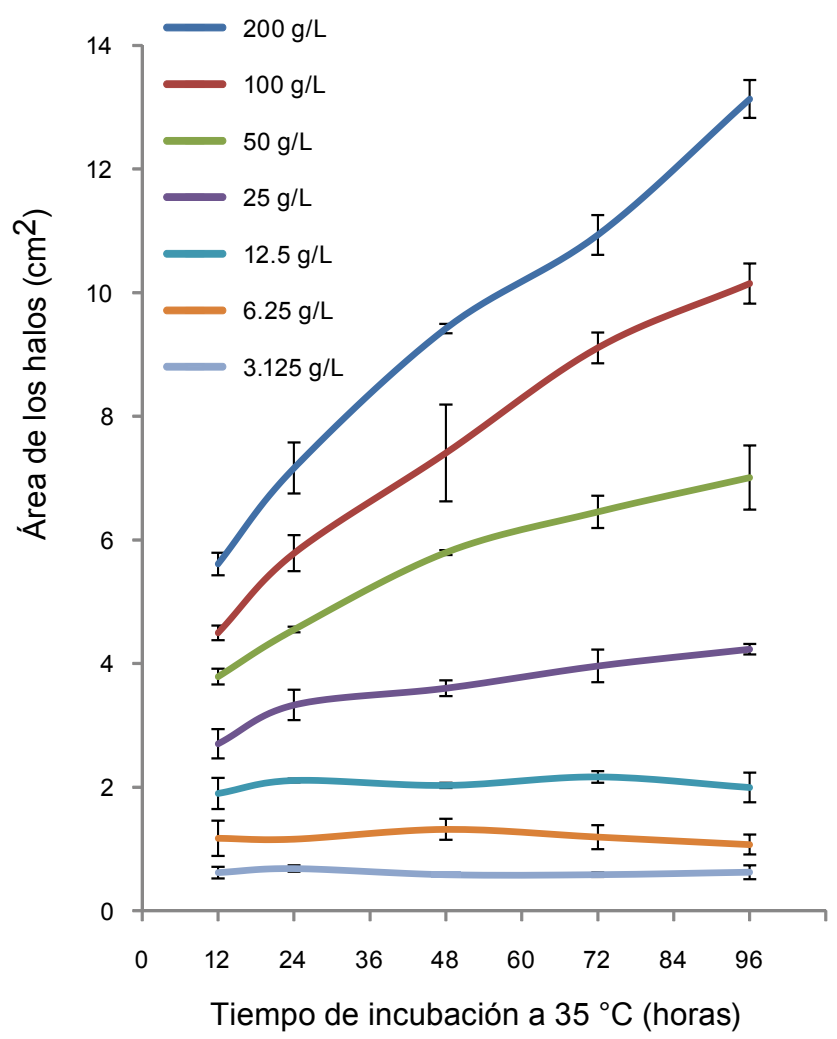

Figura 11. Comparación del área de los halos H5 de diferentes concentraciones de $\mathrm{RL}$ a diferentes tiempos de incubación. Barras verticales indican la desviación estándar de cada punto.

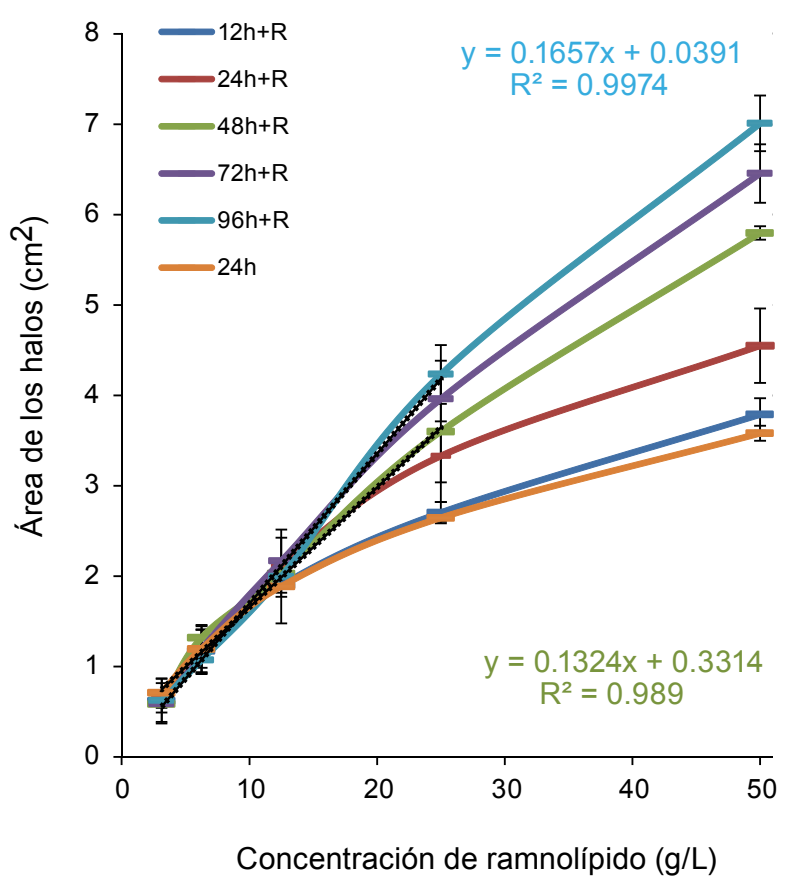

Figura 10. Gráfico del área de los halos H5 en placas de agar CTAB/MB incubadas a diferentes tiempos. Detalle de las conconcentraciones de RL menores a $50 \mathrm{~g} / \mathrm{L}$. Placas con 24 horas de post-incubación a $4{ }^{\circ} \mathrm{C}$ (refrigeración) se indican con "+R". Barras ververticales indican la desviación estandar de cada punto.

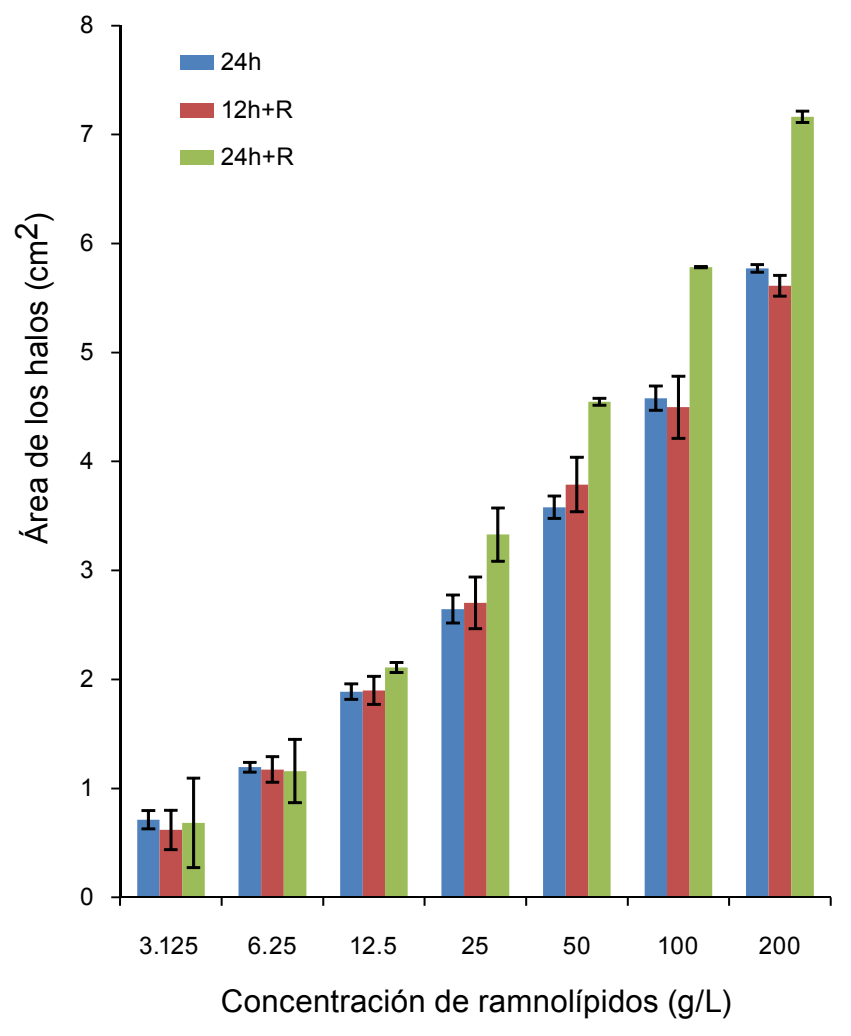

Figura 12. Gráfico comparativo entre el área de los halos de las las placas con 24 horas en frío $(12 h+R$ y $24 h+R)$ y las no refrigeradas $(24 \mathrm{~h})$. Barras verticales indican la desviación estándar de cada punto. 


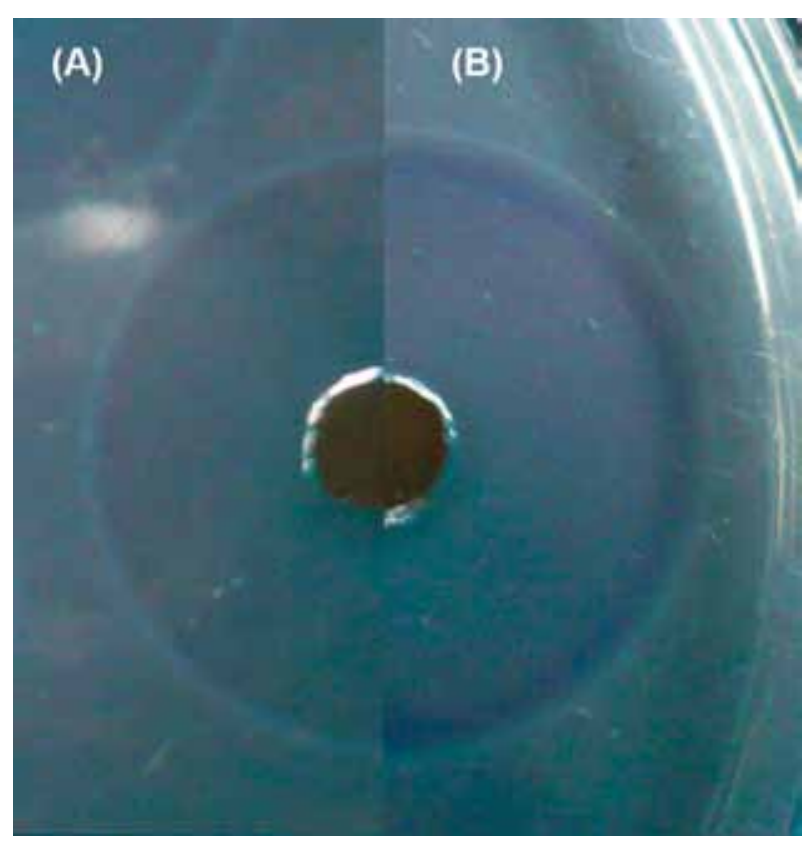

Figura 13. Halo de acomplejamiento sin refrigeración $(A)$ y luego de 24 horas de incubación a $4^{\circ} \mathrm{C}(\mathrm{B})$. Nótese el incremento en el tamaño del halo y la intensificación del color azul.

sivos, se observa que conforme se incrementa la concentración de $\mathrm{RL}$, las diferencias se hacen más significativas entre los tiempos de incubación; gráficamente se puede apreciar como las rectas se vuelven más empinadas conforme aumenta la concentración de RL (Figs. 11 y 12 ).

Al calcular el ratio RL:CTAB en los puntos de "equilibrio" se encontró que no parecía guardar una relación equimolar (1:1) ni tampoco un ratio molar constante, sino más bien un ratio variable dependiente de la concentración (Tabla 2).

En relación con el efecto de la incubación en frío $(+\mathrm{R})$ la prueba ANOVA y la prueba post-hoc HSD de Tukey mostraron que no existían diferencias significativas entre los tiempos $24 \mathrm{~h}$ ( 24 horas a $35^{\circ} \mathrm{C}$ sin refrigeración) respecto a $12 \mathrm{~h}+\mathrm{R}$ (12 horas a $35^{\circ} \mathrm{C}$ seguidas de 24 horas de refrigeración), pero sí respecto al mismo periodo pero con refrigeración $(24 \mathrm{~h}+\mathrm{R})$.

Tabla 2. Cálculo del ratio molar RL:CTAB en los halos formados con las diferentes concentraciones de RL. Asumiendo el P.M. promedio del RL como $650.795 \mathrm{~g} / \mathrm{mol}$ y del CTAB como $364.45 \mathrm{~g} / \mathrm{mol}$.

\begin{tabular}{ccc}
\hline $\begin{array}{c}\text { Concentración } \\
\text { de RL }(\mathrm{g} / \mathrm{L})\end{array}$ & $\begin{array}{c}\text { Área de } \\
\text { H5 }\left(\mathbf{c m}^{2}\right)\end{array}$ & $\begin{array}{c}\text { Ratio } \\
\text { RL:CTAB }\end{array}$ \\
\hline $\mathbf{3 . 1 2 5}$ & $0.635^{\mathrm{b}}$ & 1.34 \\
$\mathbf{6 . 2 5}$ & $1.185^{\mathrm{b}}$ & 1.44 \\
$\mathbf{1 2 . 5}$ & $2.014^{\mathrm{b}}$ & 1.69 \\
$\mathbf{2 5}$ & $3.601^{\mathrm{a}}$ & 1.89 \\
$\mathbf{5 0}$ & $5.796^{\mathrm{a}}$ & 2.35 \\
$\mathbf{1 0 0}$ & $7.407^{\mathrm{a}}$ & 3.68 \\
$\mathbf{2 0 0}$ & $9.421^{\mathrm{a}}$ & 5.78 \\
\hline
\end{tabular}

(a) : Promedio de las áreas de los halos obtenidos a las $48 \mathrm{~h}+\mathrm{R}$

(b) : Promedio de las áreas de los halos de todos los tiempos al alcanzar el equilibrio.

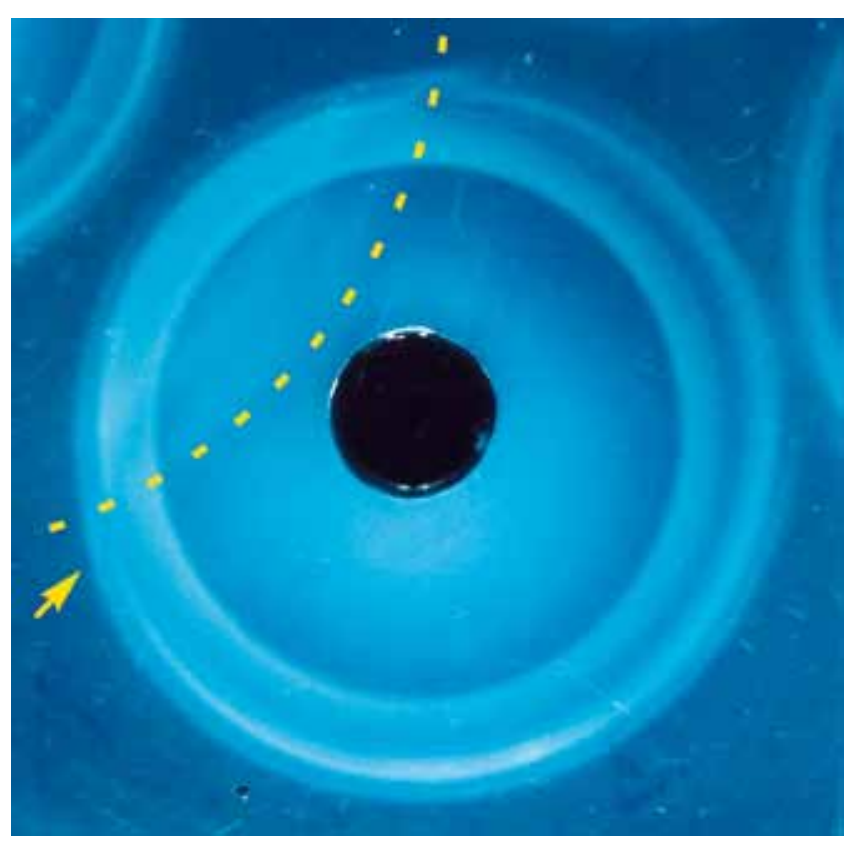

Figura 14. Halos de precipitación obtenidos antes de la refrigeración (izquierda) y luego de la refrigeración (derecha). Nótese la mejor separación de los halos y la formación de nuevos márgenes.

Entre los halos de las placas de 24 horas con refrigeración $(24 \mathrm{~h}+\mathrm{R})$ se observa un incremento en el área de entre $24.1 \%$ y $27.1 \%$ dependiendo de la concentración de RL respecto a los halos de las placas de 24 horas sin refrigeración (24h).

En términos cualitativos, el frío ocasiona que el color azul de los halos de acomplejamiento se intensifique (Fig. 13); así mismo, la desaceleración de la difusión del RL permite que los halos de precipitación se separen y definan mejor, haciéndose distinguibles algunos halos intermedios (HX.5) (Fig. 14).

\section{Evaluación del efecto de la concentración de CTAB en el} agar.- En general cuanto mayor es la concentración de CTAB, menor es el tamaño de los halos (Fig 15); no obstante, los halos que se forman se aprecian más definidos y nítidos. Por el contrario, concentraciones más bajas de CTAB generan halos más grandes pero tienden a ser más difusos y tenues; en el caso de las placas con $0.05 \mathrm{~g} / \mathrm{L}$ de CTAB, los halos se observan demasiado difusos para poder siquiera ser medidos con precisión. En todas las concentraciones el comportamiento de la curva parece ser la misma descrita anteriormente; pero cuanto mayor es la concentración de CTAB en el medio, el punto de quiebre pareciera desplazarse ligeramente hacia la derecha (hacia una mayor concentración de RL).

Un hallazgo importante respecto al tamaño de los halos, es que la variación en las áreas no es proporcional al cambio en el contenido de CTAB del medio: el incremento entre área de los halos de las placas de $0.3 \mathrm{~g} / \mathrm{L}$ CTAB y respecto a las de $0.4 \mathrm{~g} / \mathrm{L}$, varía entre 7.85 y $54.02 \%$ dependiendo de la concentración de $\mathrm{RL}$; entre las de $0.2 \mathrm{~g} / \mathrm{L}$ respecto a las $0.3 \mathrm{~g} / \mathrm{L}$, la variación está entre 17.20 y $30.80 \%$; y entre las $0.1 \mathrm{~g} / \mathrm{L}$ respecto a las $0.2 \mathrm{~g} / \mathrm{L}$, el incremento oscila entre 23.58 y $68.02 \%$.

\section{Discusión}

Nuevo método de revelado de las placas.- Con el método convencional, la producción de ramnolípidos se verifica me- 


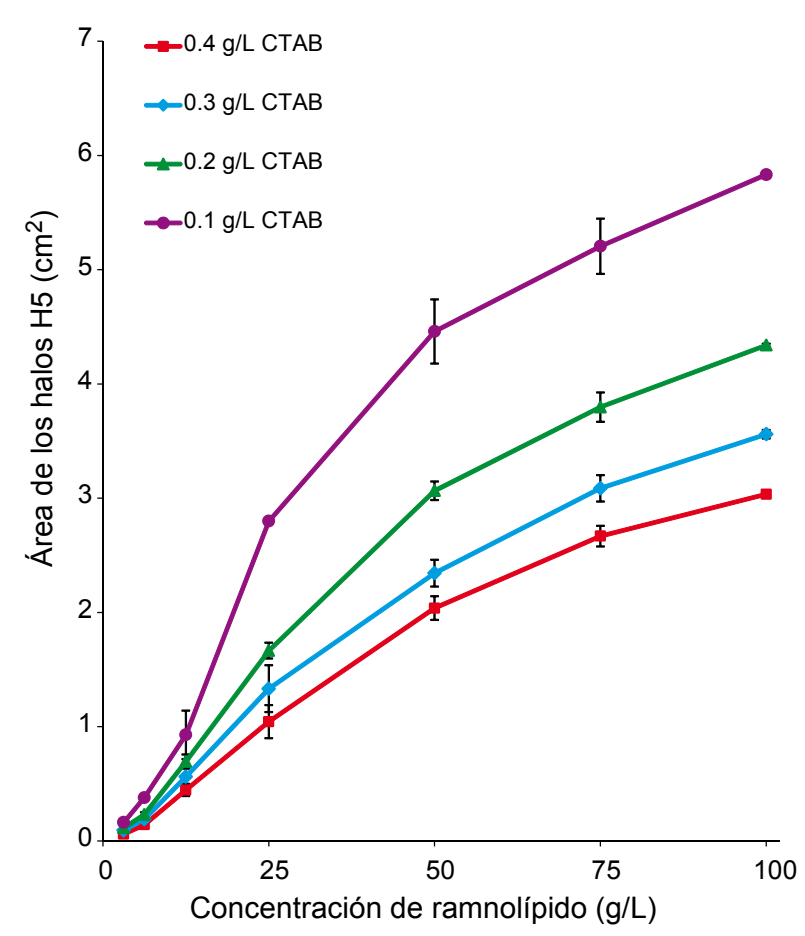

Figura 15. Gráfico del área de los halos $\mathrm{H} 5$ en placas de agar $\mathrm{CTAB} / \mathrm{MB}$ con diferentes concentraciones de CTAB. Detalle de las concentraciones de RL menores a $100 \mathrm{~g} / \mathrm{L}$. Barras verticales indican la desviación estandar de cada punto.

diante la formación de halos azules alrededor de las colonias/ pocillos. La formación de estos halos posiblemente se deba a la interacción iónica y acomplejamiento entre RL, CTAB y MB, y a una posible interacción redox con el $\mathrm{MB}$ (lo que le da el color azul característico); no obstante, el mecanismo exacto aún no ha sido dilucidado.

Los RL son de alguna manera moléculas complejas, por lo que la formación del complejo CTAB/MB-RL no lo inmoviliza totalmente y el RL puede seguir difundiendo, por lo tanto el tamaño de los halos dependerá del momento exacto en el cual son medidos, por eso el halo aparenta estar en un estado transicional tiempo-dependiente (Pinzon \& Ju, 2009a). Con el método original, muchas veces es difícil distinguir los bordes o los halos en sí; el nuevo método hace que los halos sean más fáciles de observar y de medir. El pKa de los RL está entre 4.28 - 5.50 dependiendo de su estructura predominante y su concentración
(Lebrón-Paler et al. 2006). A pH bajo, los RL pierden su carga negativa y se rompen las interacciones electrostáticas del CTAB/ MB-RL. A pH menor de dos, el exceso de $\mathrm{H}+$ parece también alterar la interacción RL-agua, por lo que el RL pierde afinidad por el agua y precipita formando halos blancos (Fig. 16).

La precipitación del RL presenta algunas ventajas: En primer lugar, al precipitar los RL se hacen insolubles y se inmovilizan de forma efectiva, por lo que es posible controlar con mayor precisión el tiempo de migración del complejo. En segundo lugar, con la técnica convencional, muchas veces es difícil distinguir los halos dado que ocasionalmente se muestran transparentes o difusos, y en ocasiones la producción de los pigmentos difusibles propios de Pseudomonas dificulta aún más la observación de los halos (Pinzón \& Ju 2009a). El nuevo método hace que los halos sean más fáciles de observar y de medir; además, la disminución del $\mathrm{pH}$ hace que el agar sea más transparente debido a la reducción del azul de metileno.

Usando la técnica convencional, hasta el momento se han descrito tan sólo 5 zonas en los halos (Pinzon \& Ju, 2009a); mientras que con la nueva técnica se ha podido visualizar y describir hasta 11 halos. Este patrón particular de halos podría corresponder a diferentes grados de interacción entre el CTAB y los diferentes tipos de RL; no obstante, son necesarios mayores estudios para poder determinarlo con seguridad. De hecho, el área de las capas internas (H2, H3) y las capas intermedias (HX.5) tienden a variar dependiendo de la cepa y de las condiciones del proceso de producción y purificación del RL, por lo que se podría suponer que la formación y tamaño de dichas capas está relacionado a las estructuras predominantes que componen la mezcla de RL inoculado. Estructuras diferentes presentan pesos moleculares diferentes y dominios de interacción hidrofóbica/ hidrofílica diferente, por lo que es de suponer que presenten comportamientos migratorios diferentes.

En términos prácticos, la medición de los halos internos no es totalmente conveniente debido a la variabilidad que presentan, por ello es preferible la medición del halo externo (H5) ya que es el único del que se tiene certeza de su presencia y tamaño.

Relación entre concentración de RL y área de los halos.La medición inicial de las áreas de los halos y la gráfica de sus promedios mostró una curva claramente no-lineal con un punto de quiebre alrededor de 75 a $100 \mathrm{~g} / \mathrm{L}$ de concentración de RL. Este resultado refuta la aparente linealidad entre la concentración de RL y las áreas de los halos propuesta inicialmente por Siegmund \& Wagner (1991) y luego por Pinzon y Ju (2009a),

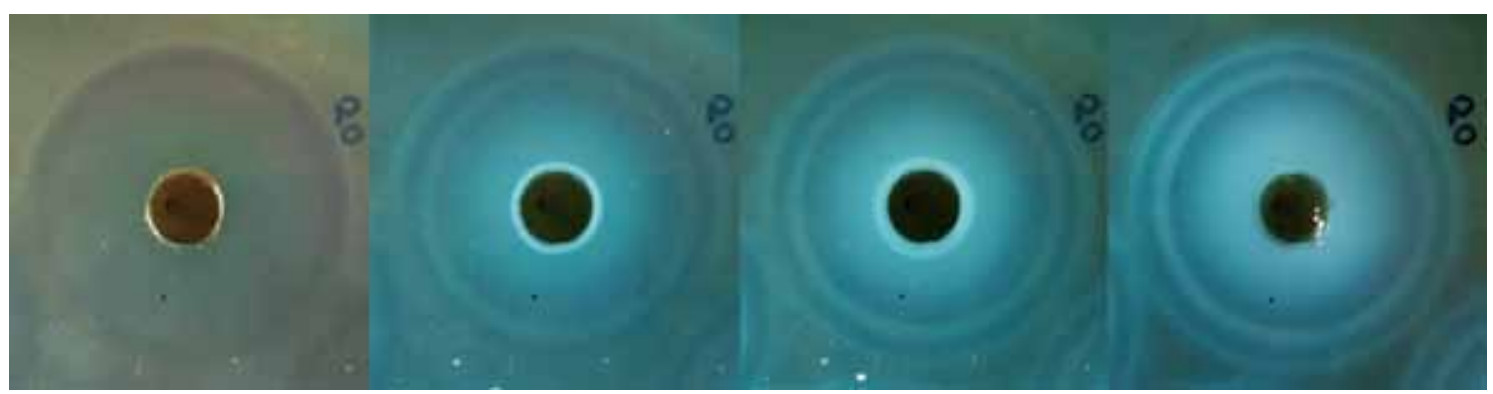

Figura 16. Secuencia fotográfica de la formación de los halos de precipitación luego de añadir $\mathrm{HCl} 1 \mathrm{~N}$.(A) Antes de añadir $\mathrm{HCl}$, después de: (B) 30 segundos, (C) un minuto, (D) 15 minutos. 


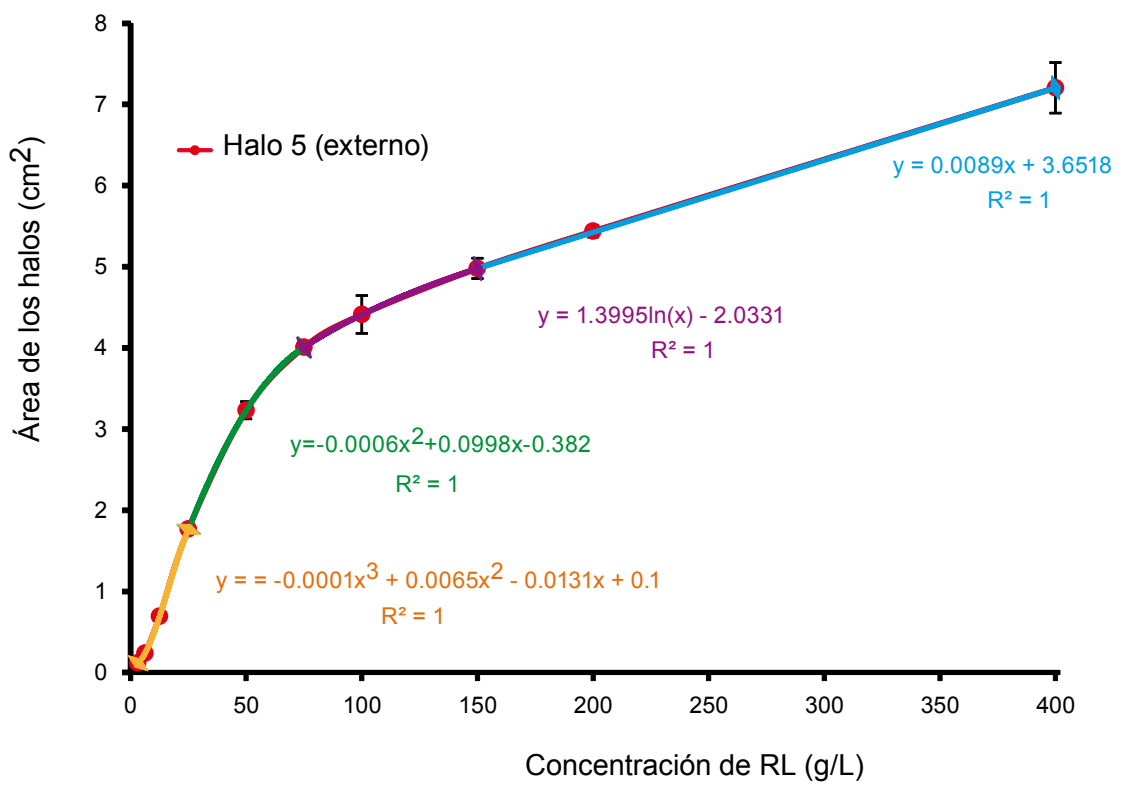

Figura 17. Gráfico del área de los halos de precipitación en placas de agar CTAB/MB. Ubicación aproximada de los puntos de quiebre (BP) y fórmulas de regresión de cada segmento. Barras verticales indican la desviación estandar de cada punto.

aunque estos últimos posteriormente se rectificaron al manifestar dificultades para correlacionar cuantitativamente de forma precisa ambas variables.

La difusión del RL parece ser dependiente de su concentración: difunde a través del agar hasta que la formación del complejo CTAB/MB-RL ralentiza su migración. Cuando la concentración de RL se incrementa y sobrepasa la concentración "crítica" (punto de quiebre), la difusión del RL (o del complejo CTAB/MB-RL) se desacelera todavía más. Este resultado podría explicarse por la naturaleza compleja de la interacción entre el $\mathrm{RL}$, el CTAB y el MB, pues ya no sólo se trataría de una interacción del tipo par-iónico. Más aún, la interacción hidrofóbica CTAB-RL y RL-RL tendría que ser tomada en cuenta también: en concentraciones altas de RL, es probable que la interacción hidrofóbica domine sobre las interacciones hidrofílicas (con el agua) e iónicas (con el CTAB/MB); como resultado, las moléculas presentan comportamientos diferentes y por lo tanto velocidades de migración diferentes.

Dado que la curva no se ajusta a ningún sistema de regresión simple, matemáticamente sería necesario aplicar una técnica de regresión segmentada con varios puntos de quiebre y un sistema de ecuaciones de al menos 3 o 4 elementos (Fig. 17). Pero, en términos prácticos, el hecho de presentar un comportamiento variable y un patrón de migración de dicha naturaleza, dificulta una correlación precisa entre las áreas de los halos y la concentración de RL. Esto obliga a requerir de otra técnica de cuantificación para un análisis cuantitativo más fino. No obstante, dado que la curva siempre tiene una tendencia ascendente, aún es útil como método de screening semi-cuantitativo, ya que si bien no es posible determinar de manera precisa cuánto RL se ha producido, aún es posible comparar y distinguir cepas con productividad significativamente diferentes bajo condiciones similares.

Evaluación del efecto del azul de metileno en el agar.- El azul de metileno $(\mathrm{MB})$ es un componente catiónico clave en la técnica convencional ya que la producción de RL se verifica mediante de la formación de los halos azules característicos. El sutil cambio del color azul en el agar posiblemente se deba a la ligera variación de la absorvancia del azul de metileno luego de la formación el complejo CTAB/MB-RL (Pinzon \& Ju, 2009a) o a un cambio redox del MB.

Con la nueva técnica de revelado, estrictamente no se visualizan los halos de color azul, porque con el uso de $\mathrm{HCl}$ el color azul finalmente se pierden o se ocultan tras los halos de precipitación opacos. Esto no signfifica que el uso del MB podría ser innecesario, porque se puede observar que los halos de precipitación que se forman en las placas sin $\mathrm{MB}$ se muestran difusos, llegando al punto que a veces ni siquiera se distinguen ni se diferencian los halos internos (ver Fig. 6). Entonces, la importancia del MB no solamente radica en la formación de color sino también en la formación del propio complejo CTAB/MB-RL, el cual ralentiza la migración del CTAB, lo que verifica la importancia del uso del $\mathrm{MB}$ en la técnica, tanto la convencional como la modificada.

Influencia del diámetro de los pocillos y el volumen de inóculo.- Dado que no se encontraron diferencias significativas en el área de los halos en relación al tamaño de los pocillos para un mismo volumen de inóculo $(10 \mu \mathrm{L})$, se llegó a la conclusión que es más conveniente el trabajo con un diámetro de $5.5 \mathrm{~mm}$, ya que es más sencillo trabajar con pocillos de mayor tamaño, tanto al momento de hacer las perforaciones como al momento de la inoculación. Se estableció como volumen ideal $20 \mu \mathrm{L}$ para los pocillos de $5.5 \mathrm{~mm}$ de diámetro ya que es un volumen significativo para trabajar y reduce ligeramente la distorsión que podría ser causada por el aumento de la cantidad de RL.

En relación a la equivalencia de cantidad de RL inoculado con respecto al volumen, el hecho de encontrar diferencias significativas entre las medias de las área de los halos H3, H3.5, H4 y H5 de diferentes inóculos cuyo contenido de RL (concentración $\times$ volumen) era supuestamente el mismo, indica que la migración 
de los RL está más en función de su concentración a determinado volumen y no a su cantidad neta (masa o moles) y que el tamaño del halo está más influenciado por la concentración de RL que por el volumen inoculado.

Evaluación del tiempo de incubación y del efecto del frío.- El tiempo de incubación de las placas es determinante en el tamaño de los halos. Las gráficas (Figs. 13 y 14) muestran que a mayor tiempo de incubación los halos alcanzan mayor tamaño; sin embargo, los resultados de esta prueba también muestran que existe la posibilidad que haya un "área de máxima migración" donde la inmovilización de los ramnolípidos es total.

La difusión del RL parece ser proporcional al tiempo de incubación pero dependiente de la concentración de RL (Fig. 15) ya que las concentraciones más altas tienden a migrar más rápido en un tiempo determinado. Luego, la velocidad de difusión pareciera experimentar una ligera desaceleración en el momento que el área del halo se acerca a su "máximo", momento en que finalmente la difusión aparentemente se detiene.

Los RL de las concentraciones más bajas aparentemente logran quedar inmovilizados dentro de las 12 horas de incubación a $35^{\circ} \mathrm{C}$ y 24 horas a $4{ }^{\circ} \mathrm{C}(12 \mathrm{~h}+\mathrm{R})$, alcanzando una supuesta relación lineal entre la concentración del RL y el área de los halos formados; a diferencia de los RL de las concentraciones mayores a $25 \mathrm{~g} / \mathrm{L}$ los cuales no logran acercarse al punto de inmovilización en el tiempo máximo programado en el experimento $(96 \mathrm{~h}+\mathrm{R}$ : $96 \mathrm{~h}$ a $35^{\circ} \mathrm{C}$ y $24 \mathrm{~h} \mathrm{a} 4^{\circ} \mathrm{C}$ ); es por ello que se sospecha que las concentraciones más altas requerirían progresivamente de muchísimo mayor tiempo para alcanzar sus respectivas "áreas de máxima migración”. Por otra parte, es probable que las aparentes "áreas de máxima migración" estén relacionadas al contenido de CTAB en las placas; no obstante, al calcular el ratio RL:CTAB de dichos puntos se encontró un ratio variable dependiente de la concentración de RL. Este resultado concuerda con lo obtenido por Pinzon y Ju (2009a) al calcular los ratios de acomplejamiento molar RL:CTAB+MB de los halos obtenidos a 48 horas de incubación, lo que una vez más representa una dificultad para poder correlacionar cuantitativamente el área de los halos y la concentración de RL.

En términos prácticos, el tiempo de incubación ideal sería de 48 horas ya que es el mínimo tiempo necesario para que por lo menos las concentraciones menores a $25 \mathrm{~g} / \mathrm{L}$ alcancen su "áreas de máxima migración" o estén muy cercanos a éste; lo que nos asegura que los halos formados en dichas concentraciones de RL hayan alcanzado su tamaño máximo aparente y de esa forma poder reducir un poco la variación causada por el tiempo de incubación variable y contrarrestar de alguna manera el estado transicional tiempo-dependiente del RL a concentraciones menores a $25 \mathrm{~g} / \mathrm{L}$. En términos cualitativos, la post-incubación a $4^{\circ} \mathrm{C}$ presenta también ventajas adicionales, ya que no sólo intensifica el color azul de los halos de acomplejamiento (Gunther IV et al., 2005; Pinzon \& Ju 2009a); sino que ayuda a separar y definir mejor los halos de precipitación, permitiendo diferenciar algunos halos intermedios.

Evaluación del efecto de la concentración de CTAB en el agar.- Respecto a la variación de la concentración de CTAB en el agar, se obtuvieron resultados semejantes a los obtenidos por Pinzon y Ju (2009a); aunque a diferencia de ellos, con la nueva técnica de revelado sí fue posible detectar RL con concentraciones menores a $50 \mathrm{~g} / \mathrm{L}$ para placas con CTAB a $0.4 \mathrm{~g} / \mathrm{L}$ y $0.3 \mathrm{~g} / \mathrm{L}$.
En general, cuanto mayor es la concentración de CTAB, menor es el tamaño de los halos y la capacidad de discriminación entre concentraciones de RL cercanas disminuye; no obstante, los halos que se forman se aprecian más definidos y nítidos. Por el contrario, concentraciones más bajas de CTAB permiten mejor discriminación para concentraciones de RL más pequeñas, pero los halos tienden a ser más difusos y tenues, sobre todo para las concentraciones más altas de RL.

El aparente desplazamiento hacia la derecha del punto de quiebre (hacia una mayor concentración de RL) conforme aumenta la concentración de CTAB en el medio, podría ser un posible indicio de la existencia de un punto de saturación con el CTAB y que el cambio en el comportamiento de la velocidad de difusión del RL estaría relacionado con la interacción RL-CTAB.

Un hallazgo importante respecto al tamaño de los halos, es que la variación en las áreas no es proporcional al cambio en el contenido de CTAB del medio, este resultado concordaría con el hecho que el ratio RL:CTAB no es constante. Este hecho evidencia que la concentración del CTAB es una variable importante a tener en cuenta ya que afecta directamente la difusión del RL. Dado que el número de moléculas de cada especie que interviene en el complejo y el número de interacciones que se dan es difícil de estimar en un momento dado, se vuelve muy complicado establecer una correlación exacta entre contenido de CTAB en el agar y tamaño de los halos formados a determinada concentración de RL; por lo que se recomienda establecer la concentración de CTAB en un valor constante y ajustar los demás parámetros.

Para efectos de la aplicación de la técnica se vio conveniente la utilización de CTAB a una concentración de $0.2 \mathrm{~g} / \mathrm{L}$, coincidentemente la misma concentración que originalmente emplearon Siegmund y Wagner (1991), ya que logra un equilibrio entre capacidad de discriminación a concentraciones más bajas de RL, además de la nitidez y definición de halos formados.

Parámetros ideales de trabajo con el método del agar CTAB MB.- Debido a la dificultad de correlacionar de forma precisa la concentración de RL y el área de los halos formados podría decirse que el método de agar $\mathrm{CTAB} / \mathrm{MB}$ no es muy apropiado para un análisis cuantitativo fino de la producción de RL. La difusión del RL no parece tener un comportamiento simple y existen numerosos factores que afectan la velocidad de migración de los RL y el área final de los halos, tales como la concentración del CTAB, concentración del RL que difunde, la cantidad de moléculas involucradas en el complejo CTAB/MB$\mathrm{RL}$, el espesor del agar, el tiempo de incubación, la temperatura de incubación, etc.

Dadas las características de la técnica, fijando algunos parámetros como: $20 \mu \mathrm{L}$ de inóculo, $0.2 \mathrm{~g} / \mathrm{L}$ de $\mathrm{CTAB}$ en las placas, 48 horas de incubación a $35^{\circ} \mathrm{C}$ seguido de 24 horas a $4^{\circ} \mathrm{C}$ y un revelado con $\mathrm{HCl}$ durante 15 minutos, en un rango de concentraciones de $\mathrm{RL}<25 \mathrm{~g} / \mathrm{L}$ la técnica podría ser aplicada como un método cuantitativo de forma efectiva.

\section{Agradecimientos}

Los autores agradecemos al FINCyT, por el financiamiento brindado, sin el cual no habría sido posible la realización de la presente investigación. 


\section{Literatura citada}

Abalos A., F. Maximo, M.A. Manresa \& J. Bastida. 2002. Utilization of response surface methodology to optimize the culture media for the production of rhamnolipids by Pseudomonas aeruginosa AT10. Journal of Chemical Technology and Biotechnology, 77:777-784. http://dx.doi.org/10.1002/ jctb.637

Christova N., B. Tuleva, Z. Lalchev, A. Jordanova \& B. Jordanov. 2004. Rhamnolipid Biosurfactants Produced by Renibacterium Salmoninarum 27BN during Growth on N-Hexadecane. Zeitschrift Für Naturforschung. C, Journal of Biosciences 59 (1-2): 70-74

Giraldo J. D., 2012. Producción de Ramnolípidos por Pseudomonas aeruginosa PB25: Evaluación de su Actividad Emulsificante y de Remoción de Metales Pesados. Tesis de Licenciatura en Biología (Microbiología y Parasitología), Facultad de Ciencias Biológicas, Universidad Nacional Mayor de San Marcos, Lima-Perú.

Gunther IV N. W., A. Nu-ez, W. Fett, \& D.K.Y. Solaiman. 2005. Production of Rhamnolipids by Pseudomonas chlororaphis, a Nonpathogenic Bacterium. Applied and Environmental Microbiology, 71(5):2288-2293. http://dx.doi.org/10.1128/ AEM.71.5.2288-2293.2005

Jadhav M. U.,S.D Kalme,D.P. Tamboli,\&S.P. Govindwar. 2011. Rhamnolipid from Pseudomonas desmolyticum NCIM2112 and its role in the degradation of Brown 3REL. Journal of Basic Microbiology 51(4):385-96. http://dx.doi. org/10.1002/jobm.201000364

Lebrón-Paler A. y otros, 2006. Determination of the Acid Dissociation Constant of the Biosurfactant Monorhamnolipid in Aqueous Solution by Potentiometric and Spectroscopic Methods. Analytical Chemistry, 78:7649-7658. http:// dx.doi.org/10.1021/ac0608826

Tong Liu, Jumei Hou, Yuhu Zuo, Sining Bi \& Jing Jing 2011. Isolation and characterization of a biosurfactant-producing bacterium from Daqing oil-contaminated sites. African Journal of Microbiology Research, 5(21):3509-3514. http://dx.doi. org/10.5897/AJMR11.684
Perfumo A., Banat, I. M., Canganella, F. \& Marchant, R., 2006. Rhamnolipid production by a novel thermophilic hydrocarbon-degrading Pseudomonas aeruginosa AP02-1. Applied Microbiology and Biotechnology, 72:132-138. http:// dx.doi.org/10.1007/s00253-005-0234-0

Pinzon N. M., 2009. Rhamnolipid Biosurfactant Production from Glycerol: New Methods of Analysis and Improved Denitrifying Fermentation. Thesis (PhD), University of Akron, Ohio-USA. http://rave.ohiolink.edu/etdc/view?acc_ num=akron 1257791610

Pinzon N. M. \& L.K. Ju. 2009a. Improved detection of rhamnolipid production using agar plates containing methylene blue and cetyl trimethylammonium bromide. Biotechnology Letters, 31: 1583-1588. http://dx.doi.org/10.1007/s10529009-0049-7

Rasband W., 2013. ImageJ 1.41o (http://imagej.nih.gov/ij). National Institutes of Health, USA.

Siegmund I. \& Wagner, F., 1991. New method for detecting rhamnolipids excreted by Pseudomonas species during growth on mineral agar. Biotechnology Techniques, 5(4): 265-268. http://dx.doi.org/10.1007/BF02438660

Wild M. y otros, 1997. Selection and partial characterization of a Pseudomonas aeruginosa mono-rhamnolipid deficient mutant. FEMS Microbiology Letters, 153: 279-285. http://dx.doi. org/10.1111/j.1574-6968.1997.tb12586.x

Yuste L. y otros, 2000. Characterization of bacterial strains able to grow on high molecular mass residues from crude oil processing. FEMS Microbiology Ecology, 32: 69-75. http://dx.doi. org/10.1111/j.1574-6941.2000.tb00700.x

Zhang G. L.,Y.T Wu,X.P. Qian, \& Q. Meng . 2005. Biodegradation of crude oil by Pseudomonas aeruginosa in the presence of rhamnolipids. Journal of Zhejiang University SCIENCE B, 6(8):725-730. http://dx.doi.org/10.1631/jzus.2005.B0725

Zhu Y., J. Gan, G. Zhang, B. Yao, W. Zhu \& Q. Meng. 2007. Reuse of waste frying oil for production of rhamnolipids using Pseudomonas aeruginosa zju.u1M. Journal of Zhejiang University SCIENCE A, 8(9):1514-1520. http://dx.doi. org/10.1631/jzus.2007.A1514 